\title{
Carotenoid Content and Color in Diploid Potatoes
}

\author{
Wenhe Lu${ }^{1}$ and Kathleen Haynes \\ U.S. Department of Agriculture, Agricultural Research Service, Vegetable Laboratory, Plant Sciences \\ Institute, Beltsville, MD 20705 \\ Eugene Wiley and Beverly Clevidence \\ U.S. Department of Agriculture, Agricultural Research Service, Phytonutrients Laboratory, Beltsville \\ Human Nutrition Research Center, Beltsville, MD 20705
}

\begin{abstract}
AdDitional index words. Solanum tuberosum, yellow flesh, neoxanthin, violaxanthin, lutein-5,6-epoxide, lutein, zeaxanthin
Abstract. The yellow pigment in potato (Solanum L. sp.) tuber flesh is caused by various carotenoids that may protect against cancer, cardiovascular disease, and macular eye degeneration. The objectives of this research were to 1) identify and quantify the carotenoids present in 11 diploid clones from a hybrid population of Solanum phureja ssp. phureja Juz. \& Bukasov-S. stenotomum ssp. stenotomum Juz. \& Bukasov and two tetraploid potato cultivars (the yellow-fleshed 'Yukon Gold' and the white-fleshed 'Superior'), and 2) determine the relationship between tuber yellow intensity and carotenoid content. Yellow intensity was measured by a colorimeter programmed to calculate a yellowness index, YI E-313. Carotenoid analyses were performed on an automated high-performance liquid chromatography system with software for integration and quantitation with detection at $450 \mathrm{~nm}$ using a diode array detector. Six major carotenoids were detected: neoxanthin, violaxanthin, lutein-5,6-epoxide, lutein, zeaxanthin, and an unknown carotenoid. Total carotenoid content in the yellow-fleshed diploid clones was 3 to 13 times higher than 'Yukon Gold' and 4 to 22 times higher than 'Superior'. Both total and individual carotenoid contents were positively correlated with tuber yellow intensity. There was an exponential relationship between total carotenoid content and tuber yellow intensity. This suggests that selecting for more intense yellow flesh will result in higher levels of carotenoids. These specific diploid clones were selected for this study because they produced at least five percent $2 n$ pollen; they have the potential to make significant contributions to improving the nutritional status of tetraploid potatoes through $4 x-2 x$ hybridizations.
\end{abstract}

Most American consumers prefer white-fleshed potatoes (Solanum tuberosum L.), and the most important U.S. potato cultivars are still white fleshed. However, 'Yukon Gold', a yellow-fleshed potato cultivar developed by Canadian potato breeders (Johnston and Rowberry, 1981), has found a niche in the United States and has opened the door to acceptance of yellowfleshed potatoes by American consumers. Since the successful introduction of 'Yukon Gold', potato breeders in the United States have renewed their efforts to develop new and improved yellow-fleshed cultivars. Although yellow-fleshed potatoes might not displace white-fleshed potatoes in North America, they have created their own market in the United States and can also be used to expand the export market to other countries where yellowfleshed potatoes are favored (Zink, 1996).

The yellow-flesh trait in potatoes is controlled by a single gene which has been mapped to the third chromosome (Bonierbale et al., 1988), with yellow flesh dominant over white flesh (Fruwirth, 1912). Modifying genes are also important because large variations in yellow-flesh intensity have been observed in segregating populations (Black, 1930; Engel, 1957; Schick, 1956). Environmental factors can exert some influences on the expression of yellow-flesh intensity. Haynes et al. (1996) showed there were significant differences in yellow-flesh intensity across environments. In their study, the clone $\times$ environment interaction was also significant, but the interaction was too small to be of practical value. They estimated broad-sense heritability for yellow-flesh

Received for publication 12 Dec. 2000. Accepted for publication 29 June 2001 Mention of a trademark, warranty, proprietary product, or vendor does not constitute a guarantee by the U.S. Department of Agriculture and does not imply its approval to the exclusion of other products or vendors that may also be suitable. The cost of publishing this paper was defrayed in part by the payment of page charges. Under postal regulations, this paper therefore must be hereby marked advertisement solely to indicate this fact.

${ }^{1}$ Visiting scientist. Home Institution: Department of Agronomy, Northeast Agricultural University, Harbin, Heilongjiang 150030, People's Republic of China. intensity on a clonal mean basis as 0.93. Haynes et al. (1994) also found that for a given clone, tuber size, as measured by weight, was negatively correlated with yellow-flesh intensity.

The impetus to develop new, improved yellow-fleshed cultivars has now expanded beyond the goal of simply developing novelty types for specialty markets. The yellow color of the potato flesh is imparted by carotenoids (Schmid and Lang, 1939). Carotenoids may protect against a variety of chronic diseases including cardiovascular disease (Gaziano et al., 1995) and certain cancers (Colditz et al., 1985). Perhaps the clearest link between specific carotenoids and a health outcome is that for lutein/zeaxanthin and age-related macular degeneration (AMD), the leading cause of severe visual impairment and blindness in the U.S. (Dept. Health and Human Services, 1997; Snodderly, 1995). As babyboomers begin to reach age 60, the number of Americans with impaired central vision due to AMD is expected to increase and have severe social and economic impacts (Dept. Health and Human Services, 1997). The macula lutea of the retina contains pigments, composed of lutein and zeaxanthin only, and low pigment density is widely considered a risk factor for AMD. Consumption of foods rich in lutein and zeaxanthin is inversely related to AMD (Seddon et al., 1994), and short-term feeding of foods rich in lutein and zeaxanthin can substantially increase macula pigment density in human subjects (Hammond et al., 1997). However, the major dietary sources of lutein and zeaxanthin, dark green leafy vegetables, are not frequently consumed in the United States. Enhancing the lutein content of more commonly consumed vegetables is a good strategy for increasing the consumption of these carotenoids and ultimately protecting human health and quality of life. The most commonly consumed vegetable, the potato, is an ideal vegetable for carotenoid, and particularly lutein, enrichment.

Von Euler et al. (1943) reported that the range of total carotenoid content for yellow-fleshed cultivars grown in northern Sweden was between 80 and $260 \mu \mathrm{g} / 100 \mathrm{~g}$ fresh weight (FW). 
Caldwell et al. (1945) observed that the total carotenoid content in 19 white-fleshed and three yellow-fleshed cultivars was 14 to $54 \mu \mathrm{g} / 100 \mathrm{~g}$ and 110 to $187 \mu \mathrm{g} / 100 \mathrm{~g} \mathrm{FW}$, respectively. Brunstetter and Wiseman (1947) found that the total carotenoid content of 'Katahdin' harvested in a relatively immature condition was 60 $\mu \mathrm{g} / 100 \mathrm{~g} \mathrm{FW}$ (recalculated values). Iwanzik et al. (1983) analyzed 13 German cultivars grown under identical conditions. Their results showed that the total carotenoid content in these cultivars ranged from 27 to $343 \mu \mathrm{g} / 100 \mathrm{~g} \mathrm{FW}$ and that the main carotenoid was violaxanthin, followed by lutein and lutein-5,6epoxide, and in lower concentrations, neoxanthin $\mathrm{A}$, and neoxanthin. They also found a positive linear relationship between flesh color and total carotenoid content.

Primitive cultivated diploid potato species have great variation in tuber flesh color. A diploid hybrid population of Solanum phureja ssp. phureja Juz. \& Bukasov-S. stenotomum ssp. stenotomum Juz. \& Bukasov (PHU-STN), originally derived from a recurrent selection project for adaptation of these shortday species to long-day growing conditions (Haynes, 1972, 1980), was evaluated extensively for specific gravity (Haynes, 2001; Haynes and Haynes, 1990; Haynes et al., 1989, 1995). However, until now, very little data were available about the carotenoid content in this population. Brown et al. (1993) found that the combined total of lutein and zeaxanthin in orange-fleshed diploid genotypes from this population was four to five times higher than the highest total xanthophyll content of the previously reported tetraploid German cultivars (Iwanzik et al., 1983). Haynes (2000), using randomly chosen male and female parents from this PHU-STN diploid population in a design II mating scheme, obtained a narrow-sense heritability estimate of 0.99 for yellow-flesh intensity.

The objectives of this research were to 1) identify and quantify the carotenoids in selected PHU-STN diploid hybrids that produced at least five percent $2 n$ pollen, and compare the carotenoid composition and total content in these diploids with two tetraploid cultivars ('Yukon Gold' and 'Superior'), and 2) determine the relationship between yellow-flesh intensity and individual and total carotenoid content over a broad range of yellow-flesh intensities.

\section{Materials and Methods}

Plant materials. Eleven diploid potato clones with flesh color ranging from white to intense yellow and that produced at least five percent $2 n$ pollen were selected for determination of yellow-flesh intensity and carotenoid content. These clones were derived from a hybrid PHU-STN population which has been adapted to the long-day growing conditions present in the United States through recurrent selection (Haynes, 1972, 1980; Haynes, 2001). Two tetraploid potato cultivars were also included in this experiment : 'Superior', which is whitefleshed, and 'Yukon Gold', which is yellow-fleshed. These diploid and tetraploid clones were planted in May 1999 on a Caribou gravelly loam soil (fine-loamy, mixed, frigid Typic Haplorthod) in Presque Isle, Maine. They were planted in the field following a plowed down timothy-clover sod on site with a soil $\mathrm{pH}$ ranging from 5.0 to 5.4. The test location was fertilized with $1200 \mathrm{~kg} \cdot \mathrm{ha}^{-1}$ of $14 \mathrm{~N}-14 \mathrm{P}-14 \mathrm{~K}$ banded in row at planting. Cultural practices were similar to those used on commercial farms in the area. No irrigation was available. Tubers were harvested in Sept. 1999. After harvest, tubers were stored at $4{ }^{\circ} \mathrm{C}, 95 \%$ relative humidity in heavy paper bags and subsequently transported to Beltsville, Md., where they were stored under the same conditions until they were evaluated for yellow-flesh intensity and carotenoid content from 3 Jan. to 9 Feb. 2000.

Measurement of Yellow-FLeSh INTENSITY. Before evaluation, tubers were removed from cold storage and allowed to warm overnight to reduce condensation. Six to eight tubers of varying sizes which had no visible external defects were chosen from each clone. Tubers were weighed to the nearest $0.01 \mathrm{~g}$ and sliced in half from the apical to distal end and patted dry on a paper towel. Each half of the tuber was measured for its yellow-flesh intensity, which was determined by a colorimeter (Colorgard System 1000; Byk-Gardner, Silver Spring, Md.) programmed to calculate a yellow-intensity index, YI E-313 (American Society for Testing Materials, 1991). The average value of the two halves of each tuber was used to indicate the yellow-flesh intensity of that tuber.

IDENTIFICATION AND QUANTIFICATION OF CAROTENOIDS. Each cut tuber was analyzed separately for carotenoid content. The skin of the tubers was removed with a knife and the remaining tuber tissue was cut into small cubes. These were then mixed and a randomized sample of $10 \mathrm{~g}$ flesh was taken and placed in a mixer jar, in which $1.0 \mathrm{~g}$ sodium carbonate, $1.5 \mathrm{~g}$ Celite (as a filter aid) and $50 \mathrm{~mL}$ tetrahydrofuran (THF) containing butylated hydroxytoluene (BHT) $(0.05 \%)$ was added. This mixture was blended for 20 min, then filtered through Whatman 1 filter paper in a Buchner funnel under suction. The extraction process was repeated until the filtrate was colorless (usually two to three extractions). No saponification was made and the combined filtrate was evapo-

Fig.1. Typical potato carotenoid chromatogram showing the peaks for neoxanthin (1), violaxanthin (2), lutein-5,6-epoxide (3), lutein (4), zeaxanthin (5), the unknown carotenoid (6), and $\beta$-apo-8'-carotenal (7).

\section{Diploid Extract}

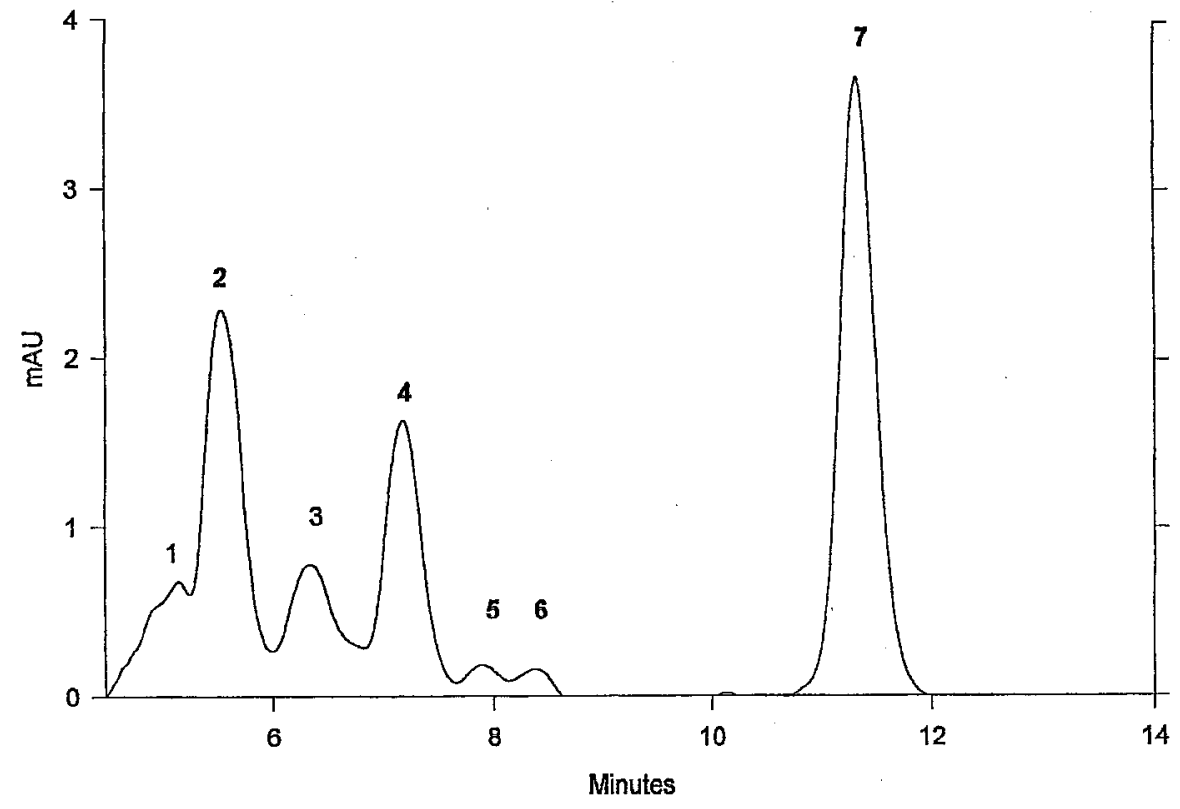




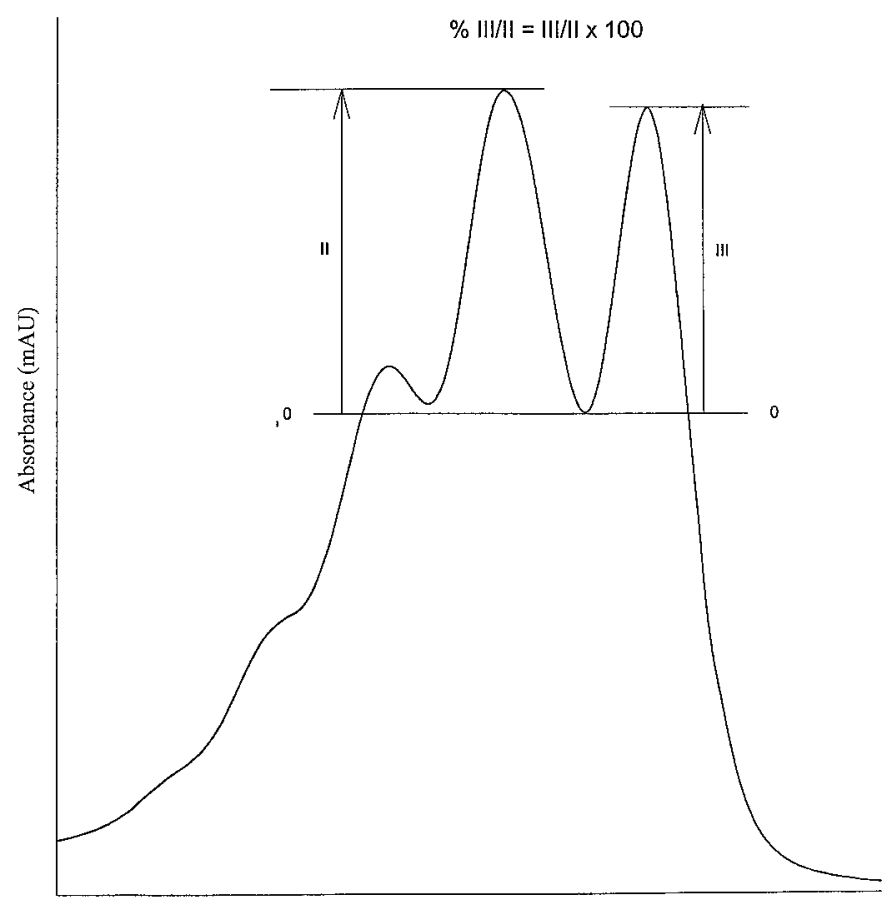

Wavelength (nm)

Fig. 2. Spectral fine structure. Calculation of \%III/II for a carotenoid.

rated on a rotary evaporator to near dryness. The concentrated extract was transferred quantitatively with methanol into a separation funnel and partitioned into methylene chloride $\left(\mathrm{CH}_{2} \mathrm{Cl}_{2}\right)$ and saturated salt water. The bottom organic layer was removed and the water layer washed with methylene chloride. This step was repeated until the water layer was colorless. Residual water was removed from the combined $\mathrm{CH}_{2} \mathrm{Cl}_{2}$ layers by drying over anhydrous sodium sulfate in a beaker and filtered through Whatman 1 filter paper in a Buchner funnel under suction. The filtrate was transferred into a round bottom flask and evaporated to dryness on a rotary evaporator. The residue was dissolved and adjusted to a volume of $100 \mathrm{~mL}$ in $\mathrm{CH}_{2} \mathrm{Cl}_{2}$ containing $\mathrm{BHT}$ $(0.01 \%)$. Two different concentrations of the final extracts were prepared, consisting of 0.8 or $0.4 \mathrm{~mL}$ of the final extracts in tubes, each containing $0.4 \mathrm{~mL}$ of internal standard solution (beta-apo- 8 'carotenal), and dried under nitrogen. The residue was redissolved in $0.4 \mathrm{~mL}$ mobile phase, transferred to an HPLC vial containing a $200 \mu \mathrm{L}$ insert, and tightly capped.

Analyses of carotenoids were performed on an automated high-performance liquid chromatography system (series 1100; Hewlett Packard, Palo Alto, Calif.) with sophisticated software for integration and quantitation with detection at $450 \mathrm{~nm}$ using a diode array detector. Analytes were separated on a $5 \mu \mathrm{m}$ reverse phase $\mathrm{C}_{18}$ analytical column $(250 \mathrm{~mm}$ length $\times 4.6 \mathrm{~mm}$ internal diameter) protected by a $5 \mu \mathrm{m} \mathrm{C}_{18}$ Brownlee guard cartridge (300 $\mathrm{mm}$ length $\times 4.6 \mathrm{~mm}$ i.d.) using isocratic elution at a flow rate of $0.80 \mathrm{~mL} \cdot \mathrm{min}^{-1}$ for $30 \mathrm{~min}$. The temperature of the column was maintained at $20^{\circ} \mathrm{C}$. The injection volume was $50 \mu \mathrm{L}$. The mobile phase consisted of $70 \%$ acetonitrile, $15 \% \mathrm{CH}_{2} \mathrm{Cl}_{2}, 15 \%$ methanol containing BHT at $1 \% / \mathrm{L}$, and $\mathrm{N}, \mathrm{N}$-diisopropylethylamine at 0.1 $\mathrm{mL} \cdot \mathrm{L}^{-1}$. The linearity and the accuracy of the detector were determined by calibrated carotenoid standards and assessed by periodic analysis of Standard Reference Material 968B (National Institute of Standards and Technology, Gaithersburg, Md.). The identity of the carotenoids neoxanthin, violaxanthin, and lutein5,6-epoxide as illustrated in Fig. 1 was based on the elution order relative to lutein (Khachik et al., 1992). The identification of these carotenoids was further confirmed by their spectral characteristics, the absorption maxima and fine structure, denoted as \%III/ II, which is illustrated in Fig. 2, when compared to published values (Britton, 1995). The identification of lutein and zeaxanthin

Table 1. Individual and total carotenoid content ${ }^{\mathrm{Z}}(\mu \mathrm{g} / 100 \mathrm{~g} \mathrm{FW})$ of 11 diploid potato clones and two cultivars.

\begin{tabular}{|c|c|c|c|c|c|c|c|c|c|}
\hline Genotype & $\begin{array}{l}\text { Flesh } \\
\text { color }\end{array}$ & YIE-313 & Neoxanthin & Violaxanthin & $\begin{array}{l}\text { Lutein-5,6- } \\
\text { epoxide }\end{array}$ & Lutein & Zeaxanthin & Unknown & Total \\
\hline \multicolumn{10}{|l|}{ Clone } \\
\hline BD296-2 & Yellow & 74.34 & 24 & 241 & 548 & 531 & 44 & 48 & 1435 \\
\hline BD316-4 & Yellow & 74.79 & 24 & 438 & 422 & 221 & 15 & 11 & 1131 \\
\hline BD326-4 & Yellow & 75.79 & 21 & 391 & 433 & 182 & 10 & 9 & 1046 \\
\hline BD322-4 & Yellow & 72.81 & 13 & 199 & 319 & 342 & 17 & 16 & 905 \\
\hline BD317-4 & Yellow & 72.43 & 17 & 172 & 299 & 174 & 10 & 10 & 682 \\
\hline BD337-3 & Yellow & 70.26 & 40 & 303 & 129 & 137 & 27 & 22 & 658 \\
\hline BD315-1 & Yellow & 71.73 & 14 & 203 & 231 & 168 & 13 & 9 & 638 \\
\hline BD283-4 & Yellow & 57.02 & 22 & 204 & 59 & 56 & 6 & 6 & 352 \\
\hline BD275-4 & Yellow & 61.68 & 10 & 160 & 55 & 62 & 14 & 6 & 308 \\
\hline BD333-4 & Yellow & 63.89 & 26 & 145 & 29 & 73 & 5 & 5 & 283 \\
\hline BD327-1 & White & 44.84 & 16 & 23 & 21 & 56 & 10 & 10 & 136 \\
\hline Average $(\%)^{\mathrm{x}}$ & & & 3 & 33 & 34 & 26 & 2 & 2 & 100 \\
\hline \multicolumn{10}{|l|}{ Cultivar } \\
\hline Yukon Gold & Yellow & 52.52 & 10 & 51 & 18 & 23 & 5 & 4 & 111 \\
\hline Superior & White & 40.31 & 11 & 19 & 9 & 16 & 4 & 4 & 64 \\
\hline Average (\%) & & & 12 & 40 & 15 & 22 & 5 & 5 & 100 \\
\hline
\end{tabular}

$\overline{\mathrm{z}}$ The individual and total carotenoid content for each clone was averaged over six to eight tubers, each tuber having two levels of dilution. Lutein was used as basis for quantitation of all xanthophylls.

yYI E-313 is the yellow-intensity index (American Society for Testing Materials, 1991). The higher the number, the more intense the yellow color. ${ }^{x}$ The average percentage of each constituent carotenoid was calculated as the average amount of each carotenoid divided by the average total carotenoid content at that ploidy level. 
Table 2. Correlation of individual ${ }^{\mathrm{z}}$ and total carotenoid content $(\mu \mathrm{g} / 100 \mathrm{~g})$ with yellow-flesh intensity (YIE-313) for a linear and an exponential relationship in potato tubers $(\mathrm{n}=83)$.

\begin{tabular}{|c|c|c|c|}
\hline Linear equation & $r$ & Exponential equation & $r$ \\
\hline $\mathrm{Neo}=-0.3833+0.3068 \mathrm{Yie}$ & $0.35^{* *}$ & $\mathrm{Neo}=6.0604 \mathrm{e}^{0.0165 \mathrm{Yie}}$ & $0.44^{* *}$ \\
\hline Viol $=-367.5235+8.8115 \mathrm{Yie}$ & $0.77^{* *}$ & Viol $=1.0337 \mathrm{e}^{0.0764 Y i e}$ & $0.90^{* *}$ \\
\hline Lut56ep $=-620.5905+12.8631$ Yie & $0.78^{* * *}$ & Lut56ep $=0.0946 \mathrm{e}^{0.1086 \mathrm{Yie}}$ & $0.92^{* *}$ \\
\hline Lut $=-385.8624+8.5689 \mathrm{Yie}$ & $0.66^{* *}$ & Lut $=0.8942 \mathrm{e}^{0.0744 \mathrm{Yie}}$ & $0.87^{* *}$ \\
\hline $\mathrm{Zea}=-17.2036+0.4956 \mathrm{Yie}$ & $0.47^{* * *}$ & $\mathrm{Zea}=1.0553 \mathrm{e}^{0.0368 \mathrm{Yie}}$ & $0.61^{* *}$ \\
\hline Unknown $=-17.7471+0.4832 \mathrm{Yie}$ & $0.38^{* *}$ & Unknown $=0.9386 \mathrm{e}^{0.0360 \mathrm{Yie}}$ & $0.57^{* *}$ \\
\hline Carot $=-1409.3111+31.5291 \mathrm{Yie}$ & $0.83^{* *}$ & Carot $=2.9419 \mathrm{e}^{0.0776 \mathrm{Yie}}$ & $0.95^{* * *}$ \\
\hline
\end{tabular}

${ }_{\mathrm{z}} \mathrm{Neo}=$ neoxanthin, Viol = violaxanthin, Lut56ep $=$ lutein-5,6-epoxide, Lut $=$ lutein, Zea $=$ zeaxanthin, Unknown $=$ unknown carotenoid, Carot $=$ total carotenoid, and Yie $=$ YIE-313.

${ }^{* * *}$ Significant at $P<0.01$.

was determined by purified standards (Indofine Chemicals, Somerville, N.J.).

Statistical Analysis. Average yellow-flesh intensity was calculated for each tuber of each clone. Simple linear correlations of tuber weight with yellow-flesh intensity and total carotenoid content were calculated by clone. The average yellow-flesh intensity was also plotted against individual and total carotenoid content: the simple linear correlation and a correlation based on an exponential relationship were computed.

\section{Results and Discussion}

CAROTENOID COMPOSITION AND TOTAL CONTENT IN DIPLOID AND TETRAPLOID POTATOES. Six different carotenoids were detected in the 11 diploid potato clones: neoxanthin, violaxanthin, lutein5,6-epoxide, lutein, zeaxanthin, and an unknown carotenoid (Table 1). The same carotenoids were also found in the tetraploid potato clones, but the relative contributions of individual carotenoids were different. In the diploid clones, the main carotenoids were lutein-5,6-epoxide, violaxanthin, and lutein, followed by neoxanthin, zeaxanthin, and the unknown carotenoid. In the tetraploid clones, violaxanthin was the most abundant carotenoid, accounting for $\approx 40 \%$ of the total, followed by lutein, lutein-5,6-epoxide, neoxanthin, zeaxanthin, and the unknown carotenoid.

Total carotenoid content in diploid potatoes ranged from 136 $\mu \mathrm{g} / 100 \mathrm{~g}$ (BD327-1) to $1435 \mu \mathrm{g} / 100 \mathrm{~g}$ (BD296-2) FW. Total carotenoid content in the two cultivars, 'Superior' and 'Yukon Gold', was $64 \mu \mathrm{g} / 100 \mathrm{~g}$ and $111 \mu \mathrm{g} / 100 \mathrm{~g} \mathrm{FW}$, respectively. The yellow-fleshed diploid potato clones contained 3 to 13 times more carotenoids than the yellow-fleshed cultivar 'Yukon Gold' and 4 to 22 times more carotenoids than the white-fleshed cultivar 'Superior'. The diploid tubers were much smaller that the tetraploid tubers, and it is unknown if this size difference alone accounts for the higher concentration of carotenoids in the diploid tubers (data not presented).

Of the carotenoids identified in these potato clones, more is known about the health benefits of lutein than the other carotenoids. The diploid clones contained more lutein than the two tetraploid cultivars. The lutein content in the diploid clones ranged from 56 to $531 \mu \mathrm{g} / 100 \mathrm{~g} \mathrm{FW}$, whereas 'Yukon Gold' and 'Superior' had only $23 \mu \mathrm{g} / 100 \mathrm{~g}$ and $16 \mu \mathrm{g} / 100 \mathrm{~g} \mathrm{FW}$, respectively. Currently, there is no dietary reference intake for lutein (Food and Nutrition Board/Institute of Medicine, 2000). It is widely believed, however, that health benefits would accrue as a result of increasing lutein consumption in the United States from the estimated average intake of $1.3 \mathrm{mg} \cdot \mathrm{d}^{-1}$ (Chug-Ahuja et al., 1993). Although the effects of cooking on carotenoid content of potatoes was not assessed in this study, others have reported that the xanthophylls (neoxanthin and lutein) and the carotenes (alpha-carotene and beta-carotene) are stable under normal cooking conditions; violaxanthin, however, is easily destroyed by heat (Khachik et al., 1992). It should be noted that neoxanthin, violaxanthin, and lutein-5,6-epoxide are not found in human plasma; it is assumed that these carotenoids are not absorbed (Khachik et al., 1992, 1999).

It can be concluded that the greater yellow-flesh intensity in these diploid potato clones is due to a greater concentration of color imparting carotenoids. 'Yukon Gold' was selected as one of the control cultivars in this study because it is a yellow-fleshed potato cultivar accepted widely by U.S. consumers. The total carotenoid content of 'Yukon Gold' is within the range of yellow-fleshed German cultivars (Iwanzik et al., 1983). The highest total carotenoid level was found in the diploid clone, BD296-2, whose level is very close to the mean value of orange $\mathrm{BC}_{1}$ segregants reported by Brown et al. (1993). Therefore, these yellow-fleshed diploid clones, especially those with intense yellow flesh, such as BD296-2, BD316-4, BD326-4, and BD322-4, could be a very good germplasm source for increasing the carotenoid content in tetraploid potatoes. Because the diploids used in this study can produce at least five percent $2 \mathrm{n}$ pollen, they were all included in $4 x \times 2 x$ crosses in 2000. Seeds were obtained from some crosses and will be evaluated for their efficiency in increasing the carotenoid content in tetraploid potatoes. Recent cultivar releases from several potato breeders have demonstrated that this should be possible (Coffin et al., 1988a, 1988b; Johnston and Rowberry, 1981).

RELATIONSHIP OF INDIVIDUAL AND TOTAL CAROTENOID CONTENT WITH YELLOW-FLESH INTENSITY IN POTATO TUBERS. Both individual and total carotenoid contents were positively linearly correlated to yellow-flesh intensity in potato tubers (Table 2). The best correlation was between yellow-flesh intensity and total carotenoid content $(r=0.83, P<0.01)$, followed by lutein-5,6epoxide, violaxanthin, and lutein. However, if an exponential regression equation, instead of a linear regression equation, was used to describe their relationship, all of the correlation coefficients were higher (Table 2). Iwanzik et al. (1983) obtained a linear relationship between flesh color and total carotenoid content, but they also noticed that the relationship was nonlinear for cultivars with a very high carotenoid content. If their data are reconsidered, the scatter diagram may be more appropriately fitted by using an exponential equation. Therefore, the relationship of yellow-flesh intensity with carotenoid content in potatoes is best described by using an exponential equation.

VARIATION OF TOTAL CAROTENOID CONTENT IN DIFFERENT TUBER SIZES WITHIN A CLONE. Tuber size, as measured by weight, tended to be negatively correlated with both the yellow-flesh intensity 
and total carotenoid content in a given clone (data not presented). Considering that previous research (Haynes et al., 1994) has shown that a negative correlation exists between yellow-flesh intensity and tuber size, the negative correlation of total carotenoid content with tuber size would also be expected. However, the values of these correlation coefficients varied widely among the different clones, ranging from -0.42 to -0.97 and -0.12 to 0.94 , respectively. This wide variation may be the result of the small number (six to eight) of tubers sampled, a different range of tuber sizes among the clones, and varying yellow intensity among the clones. The negative association between tuber size and total carotenoid content suggests that for determination of total carotenoid content in any given clone, tuber size should be considered and tubers of medium size should be chosen for sampling, in agreement with the results of Haynes et al. (1994).

Extraction and analysis of the carotenoid content in potatoes is time consuming and expensive. In practical potato breeding programs, it is not realistic to analyze the carotenoid content of even a small segregating population for selection of genotypes with high levels of carotenoids. The close association of carotenoid content with yellow-flesh intensity can assure that indirect selection for high carotenoid content, especially lutein, through yellow-flesh intensity will be successful, easy to implement, inexpensive, and allow for sampling of large segregating populations. Also, because genotype $\times$ environment interactions on the expression of yellow-flesh intensity are relatively small (Haynes et al., 1996), the simple but nondestructive measurement of yellow-flesh intensity by the colorimetric method to determine carotenoid content can be accomplished early in a breeding program when the amount of plant material is small.

\section{Literature Cited}

American Society for Testing Materials. 1991. ASTM standards on color and appearance measurement. 3rd ed. Amer. Soc. Testing Materials, Philadelphia. Black, W. 1930. Notes on the progenies of various potato hybrids. J. Genet. 22:2743.

Bonierbale, M.W., R.L. Plaisted, and S.D. Tanksley. 1988. RFLP maps based on a common set of clones reveal modes of chromosomal evolution in potato and tomato. Genetics 120:1095-1103.

Britton, G. 1995. UV/Visible Spectroscopy, p. 13-62. In: G. Britton, S. LiaaenJensen, and H. Pfander (eds.). Carotenoids. vol. 1B: Spectroscopy. Birkhauser, Basel, Switzerland.

Brown, C.R., C.G. Edwards, C.-P. Yang, and B.B. Dean. 1993. Orange flesh trait in potato: Inheritance and carotenoid content. J. Amer. Soc. Hort. Sci. 118:145150.

Brunstetter, B.C. and H.G. Wiseman. 1947. Carotenoid pigments in tubers of the Katahdin variety of Irish potatoes. Plant Physiol. 22:421-437.

Caldwell, J.S., B.C. Brunstetter, C.W. Culpepper, and B.D. Ezell. 1945. Causes and control of discoloration in dehydration of white potatoes. The Canner 100:35-39, 112-122.

Chug-Ahuja, J.K., J.M. Holden, M.R. Forman, A.R. Mangels, G.R. Beecher, and E. Lanza. 1993. The development and application of a carotenoid database for fruits, vegetables, and selected multicomponent foods. J. Amer. Dietary Assn. 93:318-323.

Coffin, R., G.R. Johnston, A. McKeown, R. Tarn, J. Wilson, M. Fitts, M.K. Keenan, L. Reynolds, and B. Langenberg. 1988a. Red Gold: A yellow-fleshed red skinned potato cultivar with short dormancy and high tuber set. Amer. Potato J. 65:49-55

Coffin, R., G.R. Johnston, A. McKeown, J. Wilson, M.K. Keenan, B. Langenberg, E. Knibbe, and L. Reynolds. 1988b. Rose Gold: A yellow-fleshed, pink-red skinned, tablestock cultivar with short dormancy and full season maturity. Amer. Potato J. 65:325-332.

Colditz, G.A., L.G. Branch, R.J. Lipnick, W.C. Willett, B. Rosner, B.M. Posner, and C.H. Hennekens. 1985. Increased green and yellow vegetable intake and lowered cancer deaths in an elderly population. Amer. J. Clinical Nutr. 41:3236 .
Dept. Health and Human Services, Natl. Inst. Health, National Eye Institute. 1997. Age-related macular degeneration: status of research. (www.nei.nih.gov/news/ varmus.htm).

Engel, K.H. 1957. Grundlegende Fragen zu einem Schema fur Arbeiten mit Inzuchten bei Kartoffeln. Zuchter 27:98-124.

Food and Nutrition Board/Institute of Medicine. 2000. Dietary reference intakes for vitamin C, vitamin E, selenium and carotenoids. Natl. Acad. Press, Washington D.C.

Fruwirth, C. 1912. Zur Züchtung der Kartoffel. Dtsch. Landw. Presse 39:551$552,565-567$.

Gaziano, J.M., J.E. Manson, L.G. Branch, G.A. Colditz, W.C. Willett, and J.E. Buring. 1995. A prospective study of consumption of carotenoids in fruits and vegetables and decreased cardiovascular mortality in the elderly. Ann. Epidemiol. 5:255-260.

Hammond, B.R., E.J. Johnson, R.M Russell, N.I. Krinsky, K.J. Yeum, R.B. Edwards, and D.M. Snodderly. 1997. Dietary modification of human macular pigment density. Investigative Ophthalmol. Visual Sci. 38:1795-1801.

Haynes, F.L. 1972. The use of cultivated diploid Solanum species in potato breeding, p. 100-110. In: E.R. French (ed.). Prospects for the potato in the developing world. Intl. Potato Ctr. Symp., Lima, Peru, 17-19 July 1972.

Haynes, F.L. 1980. Progress and future plans for the use of Phureja-Stenotomum populations, p. 80-88. In: O.T. Page (ed.). Utilization of the genetic resources of the potato III. Rpt. Planning Conf., Intl. Potato Center, Lima, Peru.

Haynes, K.G. 2000. Inheritance of yellow-flesh intensity in diploid potatoes. J. Amer. Soc. Hort. Sci. 125:63-65.

Haynes, K.G. 2001. Variance components for yield and specific gravity in a diploid potato population after two cycles of recurrent selection. Amer. J. Potato Res. 78:69-75.

Haynes, K.G. and F.L. Haynes. 1990. Selection for tuber characters can maintain high specific gravity in a diploid potato breeding population. HortScience 25:227-228.

Haynes, K.G., F.L. Haynes, and W.R. Henderson. 1989. Heritability of specific gravity of diploid potato under high temperature growing conditions. Crop Sci. 29:622-625

Haynes, K.G., W.E. Potts, J.L. Chittams, and D.L. Fleck. 1994. Determining yellow-flesh intensity in potatoes. J. Amer. Soc. Hort. Sci. 119:1057-1059.

Haynes, K.G., J.B. Sieczka, M.R. Henninger, and D.L. Fleck. 1996. Clone $\times$ environment interactions for yellow-flesh intensity in tetraploid potatoes. $\mathrm{J}$ Amer. Soc. Hort. Sci. 121:175-177.

Haynes, K.G., D.R. Wilson, and M.S. Kang. 1995. Genotype x environment interactions for specific gravity in diploid potatoes. Crop Sci. 35:977-981.

Iwanzik, W., M. Tevini, R. Stute, and R. Hilbert. 1983. Carotinoidgehalt undzusammensetzung verschiedener deutscher Kartoffelsorten und deren Bedeutung für die Fleischfarbe der Knolle. Potato Res. 26:149-162.

Johnston, G.R. and R.G. Rowberry. 1981. Yukon Gold: A new yellow-fleshed, medium-early high quality table and french fry cultivar. Amer. Potato J. 58:241-244.

Khachik, F., J.S. Bertram, M-T. Huang, J.W. Fahey, and P. Talalay. 1999. Dietary carotenoids and their metabolites as potentially useful chemoprotective agents against cancer, p. 203-229. In: L. Packer, M. Hiramatsu, and T. Yoshikawa (eds.). Antioxidant food supplements in human health. Academic Press, San Diego.

Khachik, F., M.B. Goli, G.R. Beecher, J. Holden, W.R. Lusby, M.D. Tenorio, and M.R. Barrera. 1992. Effect of food preparation on qualitative and quantitative distribution of major carotenoid constituents of tomatoes and several green vegetables. J. Agr. Food Chem. 40:390-398.

Schick, R. 1956. Methoden und Probleme der Kartoffelzuchtung. Zber. dtsch. Akad. LandWiss. Berl. 5:1-40.

Schmid, L. and R. Lang. 1939. Die Farbstoffe an Gelbfleckigkeit erkrankter Kartoffelknollen. Monatsh. Chem. 72:322-326.

Seddon, J.M., U.A. Ajani, R.D. Sperduto, R. Hiller, N. Blair, T.C. Burton, M.D. Farber, E.S. Gragoudas, J. Haller, D.T. Miller, L.A. Yannuzzi, and W. Willett. 1994. Dietary carotenoids, vitamins A, C, and E, and advanced age-related macular degeneration. J. Amer. Med. Assn. 272:1413-1420.

Snodderly, D.M. 1995. Evidence for protection against age-related macular degeneration by carotenoids and antioxidant vitamins. Amer. J. Clinical. Nutr. 62(Suppl.):1448S-1461S.

von Euler, H., L. Ahlstroem, B. Hoegberg, and Sv. Tingstam. 1943. Vitamin content of foodstuffs. I. Ark. Kemi. Mineral. Geol. Ser. B 16, No. 11:8.

Zink, R. 1996. Looking to the future with yellow-fleshed potatoes. Valley Potato Grower. (Oct.):24. 